\title{
Contracultura en el turismo cultural de los espacios urbanos contemporáneos
}

\section{Counterculture of cultural tourism in contemporary urban spaces}

\author{
Gerardo Vázquez Rodríguez*
}

Citar este artículo como: Vázquez Rodríguez, G. (2018). Contracultura en el turismo cultural de los espacios urbanos contemporáneos. Revista Nodo, 12(24), 89-102.

\section{Resumen}

La ruptura del proyecto de la modernidad en términos y escalas históricas fue rápido, en menos de doscientos años el paradigma social de la evolución hacia el futuro por parte de la tecnología y la economía empezó a ser fuertemente criticado y violentado en sus bases fundamentales. Estos tiempos de crítica y cambio serían el escenario de la contracultura de la segunda mitad del siglo $\mathrm{XX}$, esta pauta de sedición tendrá como escenario principal lo urbano e industrial en decadencia. La cercanía entre personas que se da en la época permite la casi inmediata homogenización de grupos sociales que intentan dar a conocer sus ideales, los cuales no necesariamente concuerdan con el orden preestablecido de un sistema e imaginario hegemónico conocido como cultura. Así, el presente documento analiza los conceptos que dan forma y definen a la contracultura y en particular nos enfocaremos al llamado turismo cultural, fenómeno que ha subrayado la evidencia de la contracultura como huella importante de un acontecer histórico, principalmente en Europa en donde aparecen cada vez más evidencias del fenómeno. El presente artículo intenta reflexionar los procesos bajos los que se da este acontecer de nuestros tiempos.

Palabras clave: Contracultura, Cultura, Turismo Cultural, Urbe, Modernidad.

\section{Abstract}

The rupture of the project of modernity in terms and historical scales was rapid, in less than two hundred years the social paradigm of evolution towards the future on the part of technology and the economy began to be strongly criticized and violated in its fundamental bases. These times of criticism and change would be the scenario of the counterculture in the second half of the twentieth century, this pattern of sedition will have as a main stage the urban and industrial decadence. The closeness between people that occurs at that time allows the almost immediate homogenization of social groups that try to make known their ideals, which do not necessarily agree with the pre-established order of a system and imaginary hegemony known as culture. Thus, this document analyzes the concepts that shape and define the counterculture and in particular will focus on the

Fecha de recibo: 11 de mayo de 2017 • Fecha de aceptación: 05 de abril de 2018

\footnotetext{
* Doctor en Arte por la Universidad Autónoma de Barcelona. Profesor-Investigador Titular, Departamento de Investigación y Posgrado. Facultad de Arquitectura Universidad Autónoma de Nuevo León. Sistema Nacional de Investigadores Nivel II. Correos electrónicos: gerardo.vazquezrd@uanl.edu.mx; gerardo7vazquez@gmail.com
} 
so-called cultural tourism, a phenomenon that has highlighted the evidence of the counterculture as an important trace of a historical event, mainly in Europe where more and more evidence appears of the phenomenon. This article tries to reflect on the underlying processes of this occurance of our times.

Keywords: Counterculture, Culture, Cultural Tourism, City, Modernity.

\section{A modo de introducción}

$\mathrm{Al}$ igual que la cultura, la contracultura se origina desde la inmediatez circunstancial de la comprensión y la interpretación permanente del entorno y del universo que rodea al hombre; el ser humano puede percibir, interpretar, descifrar creencias y valores dominantes que afectan al individuo y al grupo en una época determinada para crear así sistemas sociales que llegan a señalar en la mayoría de la población una homogeneidad con la cual se es proclive a vivir más uniformemente y cabría considerar esto como una cultura dominante. La contracultura significa un esfuerzo por descifrar y superar la vigencia de costumbres, ideas y creencias caducas al interior de un sistema social.

Para Herrera (2009) la contracultura se nos revela como un arquetipo; el paradigma contracultural nos permite comprender el acontecer de expre-

La contracultura se puede observar permanentemente desde las narraciones y mitos antiguos como la caja de Pandora, los Argonautas, las rebeliones contra Saturno padre de los principales dioses griegos, etc. siones culturales alternativas a un sistema. Incluye manifestaciones artísticas, científicas, sociales, filosóficas, económicas y políticas, contrarias o diferentes a la cultura oficial, a la cultura del sistema; es una forma específica de ver la realidad, establece límites a lo hegemónico, formula interrogantes, introduce enigmas en el imaginario social. La contracultura se mueve para marcar nuevas tendencias y lograr cambios, aparece la mayoría de las veces sumergida y marginal por la enorme fuerza del imaginario social del sistema que establece creencias, gustos, elementos morales, patrones anquilosados, los que a su vez crean modelos de conducta y de comportamiento correctos que originan represiones muchas veces inhumanas y terribles.

La contracultura ha estado presente desde la antigüedad como contraria, rebelde, como una fuerza renovadora de lo hegemónico y establecido culturalmente. A la contracultura se le circunscribe principalmente desde un enfoque relacionado con lo artístico, expresiones musicales, arquitectura, cinematografía, pintura, etc., pero el movimiento real de una contra-ideología nos muestra que esta noción siempre ha estado presente a través de la historia no solo en las artes sino también en todas las áreas de la cultura. Históricamente, lo contario al sistema siempre ha coexistido con este como complemento perfecto para modificar y evolucionar a las culturas dominantes. La contracultura se puede observar permanentemente desde las narraciones y mitos antiguos como la caja de Pandora, los Argonautas, las rebeliones contra Saturno -padre de los principales dioses griegos-, etc. También encontramos estas contra-ideologías en las rebeliones que dieron pie a muchas de las principales religiones, léase catolicismo, budismo, luteranismo, mormonismo, islamismo y hasta -de forma más reciente- en los cultos denominados New Age. Fenómenos sociales y políticos tienen su base en las insurrecciones contra lo establecido.

En el contexto más inmediato de la modernidad, la segunda mitad de los años sesenta del siglo XX fue decisiva en la observación de manifestaciones 
simbólicas que añadirían fuerza a los movimientos contraculturales más inmediatos, de tal suerte que en 1967 se realizó en Londres el congreso denominado Dialéctica de la Liberación mientras en Norteamérica los hippies, que ya habían vertebrado una notable y espontánea organización contra la cultura establecida, celebraban la Asamblea o Verano del Amor en el barrio de Haight Ashbury en la ciudad de San Francisco a la que asistieron más de veinticinco mil personas. Mientras tanto, en Europa y en gran parte del mundo occidental, se encontraba ya maduro el icono contracultural de "Mayo del 68", que en mucho Jean-Paul Sastre inspiró y al que dio su justificación, conjuntamente con notables representantes de la contracultura internacional como Herbert Marcuse. Estos autores, entre muchos de la época, tuvieron particular influencia en denunciar las insatisfacciones sociales dominantes a partir del gran fenómeno del culturalismo del siglo xx. En los años sesenta, como herencia del movimiento hippie, surge el concepto counterculture.

Para Arce Cortés (2008) y autores como Bennett (2001) y Clark (1976) la counterculture es un concepto clave para entender a una generación de los años 60 con un descontento hacia la figura parental y de la sociedad. El término counterculture, de acuerdo con Bennett (2001), ayuda a entender la desilusión de los jóvenes de esa época acerca del control de la cultura parental y el deseo de no querer formar parte de la máquina de la sociedad. Para Clark (1976) dicho término no sólo debe entenderse como el ir en contra de la cultura parental, tanto ideológica y culturalmente, sino también como una manera suave de atacar a las instituciones que representan el sistema dominante y reproductor como son la familia, la escuela, los medios y el matrimonio. Bajo este mismo argumento, para Roszak (1969) la counterculture es más que la oposición hacia la hegemonía, la define como una technocracy, es decir, una forma social en que la sociedad industrial alcanza la integración de su organización; siendo así la counterculture una disgregación básica de la tecnología que evita las emociones humanas y creativas, por ello utiliza la tecnocracia para descender de ese sistema hegemónico y crear así un estilo de vida (Arce, 2008, p. 263). Para González (2000) la traducción literaria de counterculture sería "cultura en oposición" o "cultura a la contra", ya que el término contracultura se entiende más como una cultura marginal o nueva cultura.

Desde una visión opuesta a la idea predominante sobre la contracultura Arce (2008, p. 264) expone a autores como Fadanelli (2000), Villarreal (2000), Martínez (2000) y De Jandra (2000) quienes consideran que no existe la contracultura, ya que la gente sigue esperando que el estado brinde algún tipo de ayuda u ofrezca algo como becas, apoyos, descuentos, etc. En la actualidad, el término contracultura es utilizado para hacer referencia a aquellas acciones o actividades que tratan de salir de los estándares establecidos. Las manifestaciones de contracultura que tuvieron su desarrollo en la década de los sesenta no solo sirvieron para manifestar momentáneamente un gran desencanto con la sociedad y su sistema de valores también valieron de comienzo para la creación de abundantes subgrupos sociales que promovían la instauración de nuevas identidades contrarias a lo hegemónico; a partir de esta lógica, heterogéneos grupos formados principalmente por jóvenes hacen hincapié en la formación de diferentes propuestas cargadas de nuevas visiones y perspectivas.

\section{Espacios urbanos y turismo cultural}

A lo largo del siglo XX y en estos primeros años del siglo XXI se ha incrementado el sinsabor social hacia la uniformidad de la vida y del espacio, esto que se pretendía lograr a partir del proyecto de modernidad y racionalidad impuesto en la mayoría del mundo de occidente se ha desmoronado estrepitosamente. En estos tiempos señalados la disputa entre los ideales que consiguen ser hegemónicos dentro de un pueblo y los ideales que lo disputan y lo contradicen son evidentes a cada momento de la 
Con la instauración de la revolución de la máquina se acrecentó el desplazamiento de la población rural hacia la urbe; así cada vez una mayor cantidad de pobladores se congregaron en torno a una organización sistémica expuesta en la ciudad.

vida urbana concebida a partir de la modernidad. Tanto la cultura dominante como su contraparte, la contracultura, son manifestaciones permanentes en los espacios urbanos que surgen desde finales del siglo XIX y principios del XX.

Con la instauración de la revolución de la máquina se acrecentó el desplazamiento de la población rural hacia la urbe. De esta manera, una mayor cantidad de pobladores se congregaron en torno a una organización sistémica expuesta en la ciudad. Estas ciudades de la modernidad trajeron consigo una convivencia colectiva de población masiva que no se había experimentado en alguna otra época documentada de la humanidad. A partir de la colectividad urbana y su latente dinámica de comunicación, la unión de diversos grupos sociales afines no se hizo esperar; surgieron así en la metrópoli colectivos de individuos afines en la persecución de objetivos e intereses y que manifestaban también una afanosa instauración de sus percepciones de vida dentro de los valores predominantes del sistema. No es que estos grupos no existirán en la antigüedad pues las congregaciones son parte básica del desarrollo humano a lo largo de la historia; sin embargo nunca como en la modernidad y sus años subsecuentes se les vio tan obligados a convivir en permanente colectividad dentro de habituales escenarios espaciales.
El espacio de la ciudad y su arquitectura fueron y siguen siendo el reflejo de estas disputas entre imaginarios ideológicos que intentan prevalecer como una cultura de alto valor para todos sus habitantes; el espacio urbano y su simbología es la mejor herramienta para recrear una idea que intente prevalecer en pro de materializar una identidad, patrón de comportamiento o cultura hegemónica.

La belleza de un espacio urbano o su devastadora ruina son herramientas aplicables para relatar historias e ideologías enfocadas en pertenecer al imaginario y a los patrones de comportamiento de una población específica. Tanto la cultura como la contracultura estarían siempre supeditadas a la expresión de lo meramente físico para instaurar su valor ante un grupo de individuos.

Los procesos de simbolización existentes en la urbe contemporánea son de alto valor para el sistema, tanto a nivel interno como al exterior: una buena organización y gestión de los mismos puede provocar factores que van desde el orden de una ciudad hasta llegar a producir símbolos urbanos que crean importantes dinámicas de consumo, tanto interno como externo, a partir de hacerse atractivos por medio de su narrativa implícita.

En una de sus facetas, el turismo contemporáneo se ha especializado en dar importancia y exaltar símbolos de una identidad poblacional y urbana para atraer el consumo de otros lugares hacia ciudades o poblaciones específicas, pues la promesa de encontrar vestigios o espacios precisos donde aconteció un hecho o evento en particular, sean culturales o contraculturales, puede ser muy atractivo para el público adecuado.

Históricamente el turismo ha estado presente al menos desde el imperio romano, destinado exclusivamente a las élites. Con el desarrollo de los modernos medios mecánicos de comunicación (el ferrocarril y el automóvil), el turismo se fue transformado en una actividad accesible a una mayor cantidad de personas hasta convertirse en un fenómeno de masas. (Velázquez, 2017, p. 81). 
En estas primeras décadas del nuevo siglo se presenta un fenómeno de movilidad apostillado como turismo cultural, el cual consiste en vincular el destino turístico con sus atractivos patrimoniales, incluyendo con mayor énfasis el rubro cultural como punto de atracción. Lo anterior deriva en una diferenciación -muy escueta- que determina al "nuevo turismo" caracterizado por el aliciente cultural y se destaca por revalorizar el patrimonio histórico del lugar; en contrapartida se ubica el "viejo turismo", el cual es una expresión de la sociedad de masas y entre sus factores de enunciación se ubican los destinos semi artificiales y dotados de elementos recurrentes.

En esta breve disertación, el quid versará en torno al "turismo cultural", con mayor señalamiento en las expresiones contraculturales que se han acoplado a la dinámica turística. Es así que contemporáneamente entre las expresiones que desglosan un sentido para clarificar el concepto de "turismo cultural" se localiza la noción de "Heritage tourism" que se vincula a un propósito de resaltar el legado cultural e histórico del lugar o patrimonio de un sitio; más allá de los museos y de los lugares de recreación la ciudad es acondicionada para ser recorrida con fines turísticos patrimoniales, donde se logra destacar una narrativa atractiva y seductora que crea la atmósfera de confidencialidad y apropiación de un lugar específico.

Los elementos de identidad que prevalecen en el turismo cultural no se limitan al patrimonio histórico-artístico, sino que también comprenden las culturas populares, la producción artística y la arquitectura contemporánea. Su definición tradicional se vincula más al enunciado del producto turístico que a la actividad real que realiza el visitante durante su estancia (Generalitat de Catalunya-ICMEC, 1996), lo que genera un acoplamiento entre las narrativas de la cultura popular dominante con el elemento turístico. Estas mismas narraciones populares provocan que el turismo cultural muchas veces este alejado de discursos formales, de orígenes y motivos reales acaecidos en movimientos sociales y acon- tecimientos históricos o se ignoren secamente propuestas estilísticas e iconográficas representadas en el lugar y en el patrimonio existente. Se atribuye así una relación con la cultura como un producto que se manufactura desde las entidades de la administración pública para el consumo del turista cultural. Aunque posiblemente en este rasgo de producción de "mercancías culturales" no se limite a los actores gubernamentales sino es una dinámica que convoca a los propios ciudadanos para lograr anclar su lugar en el reconstruido mapa del turismo cultural.

\section{Cultura y contracultura en el turismo}

Para compendiar las cuestiones en torno a los términos cultura y contracultura se retomarán los elementos fundamentales que permiten una definición puntual. Si bien el concepto Cultura se relaciona como noción cardinal de valores, reglas, percepciones, estilos, actitudes que el individuo expresa conforme a sus peculiaridades y particularidades. Definamos operativamente a la Cultura como construcción de identidades y será de ahí donde se desprenda su antítesis: la contracultura; es decir, si bien la Cultura logra abarcar un espectro amplio del quehacer del individuo conforme a los distintos grupos sociales, bajo la línea de la dialéctica es posible argumentar la condición de un contrario, por lo tanto, si es concebida la idea de una Cultura así mismo emana la noción de la contracultura. La Cultura contiene un aspecto hegemónico, normativizado por reglas establecidas desde un grupo de poder, en consecuencia la idea de contracultura deriva en la contraposición de los elementos hegemónicos que rigen la Cultura desde una concepción antagonista y contraria.

La contracultura es una expresión que -al igual que la Cultura- genera propuestas de cohesión, rasgos de identidad, representaciones a través de signos y símbolos. Aunque si este criterio se dispone a un seguimiento a la línea, posiblemente la contracultura sea un derivado de la Cultura, que presenta y evidencia las contradicciones de la 
estructura social. La (contra)cultura se estratifica por medio de códigos, variaciones del lenguaje, cánones éticos y estéticos que conforman un proceso identitario a razón de cohesionar al grupo social. Por lo tanto, la cultura comprende, acopla, congrega las propuestas contraculturales a modo de someterlas y depurarle las narrativas radicales; este acto de dominación puede ser en ocasiones un simple guiño seductor del poder, y en otras oportunidades bajo el recurso de la represión con el mismo objetivo de remover la consigna contrahegemónica y rehabilitarla en coherencia con el discurso cultural homogéneo.

El turismo cultural se enmarca en una serie de estrategias de movilización, quizá hay ciudades que gocen de una cierta referencia indiscutible como punto de acción para el turista, cuestiones tales como ser la capital de una nación, por contar con atractivos turísticos que son regidos por ciertas temporadas (por ejemplo en verano y destinos como playas y cruceros); algunas por sus recursos naturales (como montañas, bosques, entre otros), por sus vestigios y monumentos históricos; pero la tendencia emergente señala los puntos limítrofes de las megalópolis, no sólo en sentido del espacio físico sino de su proyección cultural mediante expresiones coyunturales que prevalecen como insignias del lugar.

La ciudad como ingrediente de lo cotidiano no es sino un elemento simbólico. La gran urbe mitológica, divinizada e imbatible es ya un recuerdo, un afiche. A manera de metáfora la siguiente cita donde la urbe está formada por el simbolismo de sus partes y no por una solida hegemonía imperturbable: "Toda ciudad está construida, hecha para nosotros un poco según la imagen del navío Argo, cada una de cuyas piezas no era una pieza original, pero que seguía siendo siempre el navío Argo, es decir, un conjunto de significaciones fácilmente legibles o identificables" (Barthes, 2009, p. 349). Mediante la interacción de representaciones, imágenes, recuerdos, se descubren y describen "argumentos de identidad, hitos (objeto, hechos, personajes) que restablecen la memoria colectiva de las sociedades que las produjeron." (Vázquez y Soto, 2009, p. 19).

Esta discusión que se suscita en torno al turismo y sus variaciones se esboza en una disertación que sirve -para nuestros propósitos a modo de preámbulo- para describir y categorizar la problemática desde la pluma del antropólogo Marc Augé en su obra El viaje imposible, en el cual destaca:

(...) la forma de la ciudad con las formas de lo imaginario individual y colectivo y evocaré sucesivamente la ciudad-memoria (la ciudad en la que se sitúan tanto los rastros de la gran historia colectiva como los millares de historias individuales), la ciudad-encuentro, a saber, la ciudad en la que hombres o mujeres pueden encontrarse o esperan encontrarse, pero también la ciudad que uno encuentra, que uno descubre y que uno aprende a conocer como a una persona; y por fin, la ciudad-ficción, la ciudad que amenaza con hacer desaparecer a las dos primeras, la ciudad planetaria que se asemeja a otras ciudades planetarias, la ciudad de imágenes y pantallas en las que la mirada se enloquece (...), o también aquella que trata de tomar forma, virtualidad, siempre inacabada en las periferias de la ciudad antigua (Augé, 1998, p. 112).

Las sociedades de consumo han desterrado, en gran medida, la configuración de la ciudad moderna; se conservan vestigios, se acumulan estilos, se pasa por el sincretismo pero la esencia se diluye y el rescate del molde original parece una más de las formas identitarias que cubren la amalgama de discursos posmodernos sobre el cariz de la modernidad. La planeación urbana en estas nuevas formas de hacer ciudad gestiona la desacralización del patrimonio histórico para añadirlo a los elementos turísticos que eventualmente pueden motivar el arribo de más viajeros - de esta oleada del nuevo turismo- en busca de la experiencia, es por esto último que la administración de los espacios de la ciudad se diseñan alrededor de una narrativa de la "experiencia irrepetible".

El rasgo de la experiencia es un factor crucial para determinar el turismo cultural, se vincula al apren- 
dizaje, a la rememoración de la vivencia, sobre la historia no escrita en letras de oro, sobre las iniciativas más insólitas que han sido acalladas por un discurso hegemónico. El punto contradictorio se ubica en este mismo nudo de la narración, pues, aquello que se describe como único, como autentico, y que emana de propuestas reivindicativas con tintes contraculturales, se re-configura para incorporarse a los atractivos turísticos y convertirse en una seña, en una marca particular de la región que será así mismo su publicidad.

\section{Características para la integración de la contracultura}

Si bien, bajo la lógica del "nuevo turismo" la cultura es una mercancía más que se ofrece al mercado, será posible que esto mismo suceda con la contracultura. La cultura se torna como un elemento de valor de cambio; el mecanismo para incorporar las viejas narrativas contraculturales sería debilitando su poder contestatario y adoptando su estilo como parte del inmobiliario de la ciudad.

Para que se logre el objetivo de combinar de manera armónica el discurso y estilo contracultural al proyecto turístico oficial de la ciudad se tendrán que pulir las aristas que históricamente hubieran resultado incomodas e incompatibles con el poder hegemónico de la ciudad o región. Las posibles oposiciones de un discurso rebelde tendrá que ser manipuladas debidamente antes de incorporase a lo establecido, su fuerte carga de significados irreverentes ponen en entredicho lo instituido desde el sistema dominante. En relación a la repercusión de la contracultura y por qué se tendrá que aminorar para integrarse a lo establecido, Hebdige menciona:

El estilo en la subcultura viene, pues, cargado de significación. Sus transformaciones van "contra natura", interrumpiendo el proceso de "normalización". Como tales, son gestos, movimientos hacia un discurso que ofenda a la "mayoría silenciosa", que ponga en jaque el principio de unidad y cohesión, que contradiga el mito del consenso (Hebdige, 2004, p. 34).
Así la contracultura en su esencia natural busca ser un movimiento de rompimiento a lo establecido, las contra-ideologías son contingencias para la persistencia de un sistema por lo tanto es mejor integrarlas por medio de su revestido.

Bajo ese traslape narrativo donde la contracultura se apoya en el mito, se vende como un afiche, se mercantilizan los productos de la cultura como otra mercancía más en el sistema capitalista. Con el envoltorio de "contracultural" se dictan propagandas que más allá de su esencia contestataria se diluyen en una lección educativa o en una historia recreativa enmarcada en el sumario turístico.

Este formato de "turismo cultural" muestra extremos perversos en donde un campo de guerra, de exterminio, logra ser transformado en un parque temático, que incluye su inexorable souvenir; así también, se dota de la simulación donde una región puede emular otras épocas y recobrar la experiencia de las formas de vida pasadas. Todo con fines más ligados a lo lucrativo que a lo educativo.

Este tipo de turismo rebelde tiene un nicho de mercado relevante entre los jóvenes del mundo occidental quienes lejos de apropiarse de los ideales de los movimientos buscan la experiencia como modo de asimilación histórica y de moda; es una experiencia controlada que cumple las expectativas de un tour, de un paseo turístico. Hebdiger (2004) menciona que la juventud es susceptible de amplia manera a la contracultura, el mercado de oferta contracultural tiene una marcada dirección a consolidarse como acogida para el poder adquisitivo de los jóvenes de clase trabajadora, la contracultura es una opción muy viable para absorber el excedente económico resultante de los mas jóvenes.

Cabria acotar a los anterior que la clasificación contemporánea para la noción de juventud se han ampliado, los márgenes en los rangos de edad se acrecientan y se prolonga esta clasificación social. Actualmente existe considerable atención hacia la nueva generación denominada "millennials", la generación "Y", que consume gran cantidad de 
Este formato de "turismo cultural" muestra extremos perversos en donde un campo de guerra, de exterminio, logra ser transformado en un parque temático, que incluye su inexorable souvenir

productos enfocados a la nostalgia y la sucesos históricos de contracultura, sin duda el turismo cultural se ha logrado colocar como parte de las mercancías de mayor prestigio en esta comunidad.

El supuesto del "turismo cultural" con vínculo contracultural descarga el alto voltaje simbólico que presentan ciertos espacios y movimientos sociales, utiliza a modo la sustancia radical que da sentido a la expresión contestataria, pero con un nuevo matiz del código cultural que se traduce en un espacio apropiado para recreación. El turismo cultural ofrece el plus de la experiencia y la sensación de ser parte de un movimiento contracultural de resistencia.

Entre otros factores el "turismo contracultural" se ha apropiado de las ruinas de los movimientos, da un aire fresco a propuestas que en un principio circulaban fuera de la ley, convierte en símbolos los vestigios ideológicos, los revierte en referentes para el turista. Se valoriza el pasado desde una narrativa plana, sin antagonismo, como si fuera una situación que ha logrado llegar a un punto de equilibrio. La ciudad por medio de sus administradores, políticos y la iniciativa privada, transforma el patrimonio cultural en una marca comercial, es ahora un logo sublimado de la urbe, recuperando espacios donde se vivieron batallas ideológicas para coronar la derrota de los contrarios. Contemporáneamente este proceso de convertir a la metrópoli en un marketing urbano y de trocar su historia de luchas por el espacio político y simbólico para distorsionarlo al grado de mutarlo en un "parque temático" donde todos los habitantes resultan ser parte de la decoración es arduamente requerido por los gobiernos occidentales.

Algunos espacios son apropiados por su fuerte carga histórica, por sus narrativas de ser una región que se disputa el derecho de ser diferente frente a la oleada de la globalización. El turismo contracultural contempla ese gesto de "autenticidad", aunque pueda ser un lugar cercano al "turismo de masas", lo promueve como contrario a los lugares de atracción de las ciudades globalizadas; esas ciudades que parecen ser calco y copia y que se reproducen en todo el planeta. Pero las vetas de la contracultura son también devoradas por una más de la cabeza de la hidra que se apropia de todo para convertirlo en mercancía. Lugares "sagrados" se desvirtúan de su función principal y se convierten en un "paseo dominical", la nostalgia es ahora un punto clave para ofrecer un mejor producto cultural al turismo.

Como demostración de sedición y separación a la sociedad establecida, una de las narrativa más próxima de está travesía se remonta a la década de los ochenta del siglo XX; un mar de historias que se esconden en estos radicales años. Es el tiempo de las rupturas, de la escisión entre la utopía y los proyectos de nación. El tiempo de las decadencias se aproximaba, los grandes bloques económicos destinaban sus esfuerzos en una carrera armamentística que destellaba a una gran crisis. El bloque socialista ante sus inexorables virajes y golpes de mano, se dirige hacia el camino de la autodestrucción. El mundo mutilado resulta un archipiélago donde las grandes potencias buscan salvarse a pesar de los pesares. Así, el bando capitalista, de los países con mayores desarrollos de sus fuerzas productivas desenmascara sus propias contradicciones lo cual es la antesala de la recesión, el modelo se ha quebrado. Ante esas piezas sueltas se reconstruyen las identidades, sobre esas grietas se amalgama el sentido de una composición que resana los modos de vida entre la altivez de la nostalgia. Un claro ejemplo: el sistema capitalista británico consiguió una bocanada de aire fresco a 
costa de depurar los privilegios de una clase media que habría de estancarse en la rutina, y desplazando a la clase trabajadora con medidas de corte económico que los arrojaban al despojo, sus condiciones de trabajo y de vida se asemejaban a las de un siglo atrás. De la mano de "La dama de hierro", los grandes sindicatos y las viejas reivindicaciones de la clase obrera británica se desplomaban, los gremios con mayor fuerza, envilecidos por la burocracia entregaban las trincheras para reconocer la victoria del modelo neoliberal.

La clase obrera quedaba a la deriva, cientos de familias fueron desterradas de sus viviendas, las zonas fabriles se convirtieron en ciudades fantasma, los mares donde había sido derribada "la armada invencible" ahora eran la ruta de escape para los "desarrapados" que tanto cuidaba Engels con su prosa romántica. Otra salida fue hacia el interior: las familias tomaban las fábricas, no para volver a poner en marcha la producción sino para habitarlas y formar un hogar, un refugio, una cueva donde protegerse de los nuevos depredadores neoliberales.

Se reaviva la tradición de ocupar viviendas abandonadas, viejos talleres, centros laborales cerrados por motivos de la guerra económica. Los viejos anaqueles donde se apilaban herramientas, son ocupados por utensilios de cocina; los extensos patios donde se embarcaban las mercancías se transforman en el área colectiva de juego de los infantes; las centenarias estructuras de la modernidad que recubren la gala de la industrialización son ahora una humilde vivienda de familias que sobreviven en la pesadilla del neoliberalismo. De esta narrativa surge espontáneamente la subcultura del punk, un hibrido de clase obrera con gran enfado social y ocupante de las ruinas de la modernidad, el movimiento punk tendrá grandes repercusiones en la contracultura mundial de finales del siglo XX.

En distintas partes del mundo $-\mathrm{y}$ principalmente en Europa, se presenta este movimiento social de la "ocupación" que denuncia la especulación inmobiliaria, la precarización del modo de vida, la ausencia de espacios dignos en la ciudad y el reclamo del derecho a la vivienda. Un elemento para destacar en torno a la contracultura como acción emergente y respuesta a la coyuntura se da en el territorio británico donde se exponen matices de una ruptura con los símbolos locales. Desde la visión de la narrativa de las subculturas, Hebdige describe el advenimiento punk:

Por otro lado, sin embargo, se basaba en una negación del lugar. Surgía en anónimos bloques de viviendas subvencionadas, en ignotas colas de parados, quintaesencia del barrio bajo. Era vacía, inexpresiva, desarraigada. En ello la subcultura punk se distingue de los estilos antillanos que fueron sus modelos básicos. Mientras que los jóvenes negros de ciudad podían catapultarse, mediante el reggae, hacia un inalcanzable e imaginario "más allá" (África, las Antillas), los punks vivían sujetos al tiempo presente. Estaban encadenados a una Gran Bretaña sin expectativas de futuro (Hebdige, 2004, p. 93).

Esa extrañeza de un movimiento contracultural que adopta la ruptura como expresión, que desacraliza la simbología de la modernidad, que antes de negar a otros se niega a sí mismo, convierte su espacio y tiempo en una anti-utopía; el problema no es que como la «utopía» el lugar no exista, sino que su espacio es "ningún lugar", pues "como el Dadá de André Breton, el punk parecía "abrir todas las puertas", pero esas puertas "daban a un corredor circular" (Breton, 1937, en Hebdige, 2004, p. 93). El movimiento contracultural del punk asimila la ocupación como una de sus dinámicas y acciones de identidad, la rebeldía de construir castillos de arena que se erigen sobre las ruinas de los viejos monumentos de gloria de la industrialización.

\section{Conclusiones}

A modo de repaso de las ideas anteriores, la conexión entre las expresiones contraculturales y el turismo tensa su origen en un fundamento complejo, donde confluye la intención de preservar los espacios como una insignia de las luchas pasadas, mientras su otro rostro es la conversión 
en un tour, al quitar todo elemento contestatario. Es decir, el discurso de la contracultura es domesticado por las autoridades, se les reconoce como espacio de expresiones alternas a las hegemónicas, pero se anexa a la dinámica del mercado, donde las ideas de insubordinación son utilizadas como una mercancía más que, a la postre, se convertirá en un souvenir para el turista.

Como ejemplo de lo anterior, y debido a su inmediatez temporal, podríamos referir la suerte que lleva la corriente contracultural okupa, término común que se da principalmente en España y Portugal para ocupantes de espacios urbanos deshabitados y/o en ruinas, la estética particular de estos individuos es claramente reminiscente al punk. La ocupación de viejas fábricas, viviendas en los suburbios industriales es un movimiento designado a partir del vocablo inglés de "squat". Esto, en la relación con el castellano, deviene en el término de "ocupación" el cual deriva en una transgresión ortográfica y economizada con la apócope de okupa. El movimiento de ocupación es una expresión de respuesta, de defensa y apropiación del espacio. La esencia de los okupas intenta ser un reflejo de la unión de fuerza ante una lucha contra el avance de la maquinaria capitalista, de

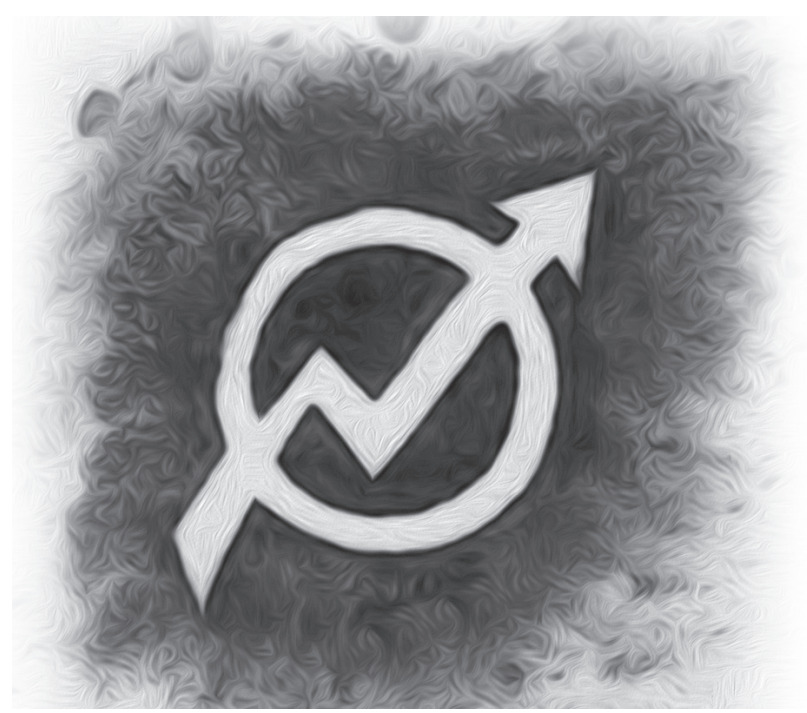

Figura 1. Símbolo del movimiento social okupa. Fuente: http://snfcomunicados.blogspot.com/ la ruta marcada por sus cuatro ruedas: el despojo, la represión, el desprecio, la explotación; para el okupante el espacio es de quien lo habita. Esté movimiento es una resolución que emerge desde una especie de exilio, un destierro dentro de las mismas ciudades; si bien las guerras y las dictaduras habrían de forzar la migración de los disidentes, esta nueva fase de la refriega del capital clausuraba las fronteras, pues, en un mundo globalizado las condiciones de miseria se habían homologado en gran parte del mundo.

Los okupas que durante cerca de tres décadas han brotado como una expresión de rebeldía contra las imposiciones de las autoridades para planificar las ciudades, y como denuncia ante la falta de oportunidades para obtener una vivienda digna. Vale recordar que si bien en este resurgir del movimiento okupa se vincula con mayor fuerza a tendencias de colectivizar los espacios y conformar puntos de referencia para la organización de los diferentes grupos que constituyen la pluralidad de tendencias políticas y sus demandas puntuales. $\mathrm{Al}$ parecer la apertura del movimiento okupa a finales de los años noventa permitió que la multiplicidad de las demandas sociales, formarán un discurso más incluyente y atractivo con lo cual se presentó un notable apoyo de la sociedad civil. Pero, justo en esa misma condición de apertura e inclusión, la enunciación de las demandas fueron incorporadas a los esquemas de las plataformas políticas con fines electorales las cuales en su accionar tratan de acoplar las denuncias como si fueran partidarios del movimiento, pero, por otro lado, ejercen presión para que se cumplan la leyes y recrudecen las acciones represivas contra los renegados y transgresores del sistema.

La paradoja deja de ser tal ante el hecho de que el sistema no lucha frontalmente para derrocar a las expresiones contraculturales, sino que busca la manera de agenciar su desarrollo para dar la estocada final y apropiarse de su producción simbólica. En relación a la apropiación de lo rebelde por parte de la preponderancia cultural desplegamos lo siguiente: "En un primer momento al sistema 
le basta con asimilar la resistencia mediante la apropiación de sus símbolos, la eliminación de su contenido 'revolucionario' y la comercialización del producto resultante" (Heath y Potter, 2005, p. 46). No es que automáticamente se vacíe de su contenido contracultural, sino que este se moldea de tal forma que, lejos de volverse incómodo para el sistema, resulta una más de sus expresiones.

A manera de ejemplo sobre el momento actual, y de cómo el turismo de contracultura trata su presencia ante las instituciones, señalaremos una variedad de casos en los que se ejemplifica el uso de enclaves urbanos de resistencia social históricos que actualmente son utilizados como iconografía turística masiva y representativa, estos casos que se muestran son parte de una publicidad extraída de páginas digitales o folletos oficiales de turismo o que bien son lugares de información reconocidos oficialmente por administraciones gubernamentales que les dan su respaldo para publicitar un espacio urbano como punto turístico:

1. La Kasa de la Muntanya en la ciudad de Barcelona, España, está construcción servía como un antiguo cuartel de la Guardia Civil que había sido edificado por la familia catalana Güell para dar seguridad al parque del mismo nombre y que fue diseñado por Antonio Gaudí. La institución armada abandona la edificación en 1983 y la propiedad pasó a manos del Ministerio de interior y después al Ministerio de hacienda; permaneció seis años sin que el Gobierno le diese uso hasta que en 1989 un grupo de activistas decidió okuparlo para acabar convirtiéndolo en un referente del movimiento antisistema barcelonés. Desde Noviembre del 2016 el ayuntamiento de Barcelona promociona su ruta turística histórica "Iconos de Gràcia" en la que se destaca el edificio okupado de la "Kasa de la Muntanya" como icono del distrito y en la que figuran 18 puntos de interés para visitar en un recorrido entre la Sagrada Familia y el Parc Güell (Guil, 2016) Así un histórico templo del movimiento okupa barcelonés que pertenece al Ministerio de hacienda y lleva tomado ilegal-

\section{El movimiento de ocupación es una expresión de respuesta, de defensa y apropiación del espacio}

mente desde 1989 se convierte en iconografía del turismo contemporáneo.

2. Camden Town es reconocido en Londres como el barrio punk emblemático, este sitio emplazado al norte de la ciudad desde sus orígenes en el siglo XVII fue habitado por migrantes irlandeses, asiáticos y artistas; es distinguido por su famoso mercado Camden Town Market, lugar que alberga a cualquier cantidad de tribus urbanas de contracultura. Los inicios del mercadillo son alrededor de 1974, cuando unos hippies de la zona comenzaron a montar puestos en los que vendían su artesanía y ropa usada; los hippies londinenses fueron precursores de las primeras ocupaciones de ruinas de la modernidad temprana y espacios en desuso dentro de esta capital, en mucho el movimiento de ocupación punk de Londres fue una réplica de las primeras comunas hippies de la ciudad. El impacto de este mercado de contracultura es tan grande que cada fin de semana alberga más de 100.000 personas y representa un icono turístico, promocionado por páginas oficiales de la capital británica; durante el día la zona está saturada de turistas y es una visita obligada, pero durante la noche se convierte en un sitio poco recomendado para el público en general (Londres.es-Camden Town, 2016).

3. Tras la caída del Muro de Berlín la casa okupa Tacheles, ubicada en un edificio en ruinas del este de Berlín, fue el centro cultural alternativo más famoso de esta ciudad Germana. Desde finales de los años ochenta hasta entrada la primera década del siglo XXI esta ocupación 
antisistema se erigió como un icono de contracultura. Muchos artistas ocuparon los edificios que habían quedado vacíos debido a la migración del Este hacia el Oeste y los ciudadanos creyeron que era una buena idea que alguien diera un uso a los edificios en vez de dejarlos derrumbarse. Tacheles se volvió un lugar emblemático de Berlín y su visita turística era imprescindible hasta su reciente cierre. Actualmente este edificio se transformo en un hotel que trata de recrear la atmósfera de contracultura impuesta por su uso común durante más de treinta año (disfrutaberlin.com, 2016).

4. El barrio okupa danés Christianshavn se encuentra en la ciudad de Copenhague, Dinamarca; era un antiguo sector militar pero en 1971 el ejército abandonó el cuartel y los okupas lo eligieron como lugar donde instalarse y hacer de esas veintidós hectáreas un espacio alternativo propicio para desarrollar una forma de vida diferente y contraria a la cultura del resto de la ciudad. La adecuación del antiguo centro militar al barrio libertario partió de una premisa básica: la creatividad. De este modo crearon talleres, tiendas, escuelas y guarderías, negocios colectivos, programas de reciclaje, anticuarios, locales para conciertos, grupos de teatro y un sinfín de espacios más basados todos en sus premisas de amor y paz. Actualmente este barrio es un lugar de vivienda okupa y residencial donde se reúnen gran cantidad de turistas que lejos de buscar un sitio espectacular esperan encontrar vestigios del significado y del simbolismo que esta barrio tuvo para la historia del país. El gobierno danés estuvo de acuerdo con esta comunidad aunque dio sólo tres años para lo que los políticos consideraran una experiencia social a corto plazo. Cuando finalizó este plazo comenzaron los enfrentamientos entre el gobierno y los okupas produciéndose durante décadas juicios, presiones, manifestaciones y números actos en contra llegándose incluso a ocupar la radio danesa en 1973. Tanto los medios impresos y digitales están repletos de informaciones que ilustran la larga historia de este sueño de rebe- lión okupa cargado de momentos de esplendor y de oscuridad (visitdenmark.es).

5. El movimiento norteamericano de contracultura "Hippie" (matiz despectivo, como si fueran una versión degradada de aquellos hípsters retratados por Jack Kerouac y celebrados por Norman Mailer) tiene uno de sus puntos de origen más emblemáticos en el barrio Haight-Ashbury de la ciudad de San Francisco, sector edificado en 1906 y abaratado por la clase media californiana. En el verano de 1967 también conocido como "Verano del Amor" se congregaron alrededor de este barrio de reminiscencias victorianas más de veinticinco mil personas en su mayoría jóvenes que trataban de generar una gran rebelión basada en ideales como la paz, el amor y la colectividad, en contrapostura al duro imaginario hegemónico de las guerras de conquista llevadas a cabo por el pueblo estadounidense. Los hippies se sabían un movimiento masivo, producto del baby oom de posguerra. No habían conocido las estrecheces y se enfrentaban a un futuro donde, según la cantinela de los futurólogos, robots y máquinas harían el trabajo desagradable, convirtiendo la gestión del ocio en un problema central. Disponían de una música, una moda, una jerga propias, de "una vida mejor gracias a la química", el lema publicitario de los años cincuenta, se había materializado en la píldora anticonceptiva y en drogas como el LSD, legal hasta octubre de 1966 (Manrique, 2017). Actualmente este barrio se ha convertido, a partir de su legado histórico de contracultura hippie, en un distrito importante para la publicidad turística de la ciudad de San Francisco. Alberga abundantes sitios de la reminiscencia de rebelión y libertad proclamada durante los años sesentas y setentas. En la página digital del turismo de San Francisco ${ }^{1}$ podemos encontrar información abundante sobre el barrio y su historia de contracultura que es narrada actualmente por comercios, restaurantes y gale-

1 http://www.sftravel.com/article/3-ways-relive-sanfrancisco\%E2\%80\%99s-summer-love-haight-ashbury 
rías de arte que dan precedente sobre el espíritu de la época.

6. En octubre de 1980 en la Ciudad de México se crea alrededor del Museo del Chopo, propiedad de la UNAM, el "Tianguis del Chopo", mercadillo de contracultura que inicialmente se instalaría solo por un mes pero que debido a la cantidad de personas que logra reunir todos los sábados se ha consolidado a lo largo de los años como un punto icónico de la cultura antisistema; abundantes tribus urbanas coexisten en este lugar intercambiando y mercadeando libros, música, arte, ropa y cultura en general. Es común encontrar tanto al Museo como al Tianguis del Chopo en páginas que los denotan como punto turístico para personas interesadas en encontrar los vestigios más sobresalientes de la contracultura mexicana ${ }^{2}$.

Desde una arista del problema, el turismo de contracultura intenta volverse iconografía de la lucha establecida contra los valores dominantes comprendidos dentro de algún momento de la historia, estos iconos se alzan como símbolos de batallas contra el sistema; con este turismo se crea un recuerdo que conmemora la sensibilidad del propio régimen hacia el cambio y también con estos monumentos urbanos se daría estructura social para el sostén mutuo de ese cambio obtenido. Las batallas que representan los iconos contraculturales podrían haber sido ganadas o perdidas; sin embargo siempre simbolizan un emblema del emprendimiento colectivo y social. Con el turismo de contracultura se podría enarbolar y dar conocimiento a las próximas generaciones sobre fórmulas aplicables y eficientes para modelar un sistema o comprender la negatividad del propio sistema para propiciar un cambio antes ciertos acontecimientos. Desde otro borde de la problemática el mismo turismo de contracultura tendrá la tendencia a trivializarse y encasillarse dentro de

2 https://www.maspormas.com/2016/03/02/tianguisdel-chopo/ una moda dedicada a jóvenes que están despertando hacia la forma de entender el mundo o se volverían enclaves de recuerdos radicales funcionales solo para generaciones mayores o grupos muy reducidos de población. En ambos casos el turismo de contracultura está ligado no obstante ligado a una narración histórica de los hechos acontecidos en sus espacios, no se puede desligar al espacio turístico de contracultura del acontecimiento que validó sus ruinas o sus recorridos. La utilización de espacios de contracultura debería ser siempre atendido desde el cuidado objetual y neutral de un símbolo histórico que marcó cambios a lo establecido.

\section{Referencias bibliográficas}

Arce Cortez, T. (2008). Subcultura, contracultura, tribus urbanas y culturas juveniles: ¿homogenización o diferenciación? Revista Argentina de Sociología. Año 6 Vol. (11). pp. 257-271. Recuperado de URL: http://www.redalyc.org/ articulo.oa?id=26911765013

Augé, M. (1998). El viaje imposible. El turismo y sus imágenes. Barcelona: Editorial Gedisa.

Barthes, R. (2009). La aventura semiológica. Barcelona: Editorial Paidós.

Bennet, A. (2001). Cultures of Popular Music. Buckingham: Open University Press.

Civitatis Berlin (2017). Tacheles Berlín. Recuperado de: https://www.disfrutaberlin.com/ tacheles

Civitatis Londres (2017). Camden Town. Recuperado de: https://www.londres.es/camden-town

Clark, J.; Hall, S.; Jefferson, T., y Roberts, B. (1976). "Subcultures, cultures and class: a theorical overview", in Hall, S., and Jefferson, T. (eds.), Resistente throught Rituals: Youth Subcultures in Post War Britain (pp. 57-71), London, Reino Unido: Editorial Taylor y Francis e-Library

Generalitat de Catalunya-Institut Català de la Mediterrània d'Estudis i Cooperació (1996). Fòrum civil Euromed. Cap a un nou escenari 
d'associació. Barcelona, España: Generalitat de Catalunya.

González Rodríguez, S. (2000). “Alternar siempre enriquece”, en Martínez Rentería, C. (ed.), Cultura Contra Cultura: Diez años de contracultura en México (pp. 29-40). México: Plaza \& Janés Crónica.

Guil, J. (21 de noviembre de 2016). Colau incluye una casa okupa en una guía turística de Barcelona. ABC Cataluña. Recuperado de http://www.abc.es/espana/catalunya/politica/ abci-colau-incluye-casa-okupa-guia-turisticabarcelona-201611210748_noticia.html

Heath, J. y Potter, A. (2005). Rebelarse vende. El negocio de la contracultura. Bogotá: Editorial Taurus.

Hebdige, D. (2004). Subcultura. El significado del estilo. Barcelona: Editorial Paidós

Herrera Zavaleta, J.L. (2009). Filosofía y contracultura. Quaderns de filosofia i ciència, Volumen (39), pp. 73-82. Recuperado de: https://www. uv.es/sfpv/quadern_textos/v39p73-82.pdf

Manrique, A.D. (2017). "Paz y amor, verano del 67”. Recuperado de: https://elpais.com/cultura/ 2017/08/04/actualidad/1501865756_160826. html

Más por más (2016). Ciudad Tianguis del Chopo. Recuperado de: https://www.maspormas.com/ 2016/03/02/tianguis-del-chopo/

San Francisco Travel (2016). 3 Ways to relive San francisco's "Summer of Love" in the haightashbury. Recuperado de: http://www.sftravel. com/article/3-ways-relive-san-francisco \% E2\%80\%99s-summer-love-haight-ashbury

Vázquez, R.G. y Soto C.K. (2009). Hacia una aproximación del imaginario de la ciudad de Monterrey en el albor del siglo XXI. En Narváez, B. (ed.) AEDIFICARE 2009, (pp. 17 34). Monterrey: Editorial Universidad Autónoma de Nuevo León.

Velázquez García, A.M. (2017). El turismo: las nuevas utopías consumistas latinoamericanas en Salazar Pérez R y Heinrich M., El Rostro difuminado de la sociedad 2020 en América Latina (pp. 81-108). Buenos Aires: El Aleph.

Visit Denmark (2018). Christiania Recuperado de: http://www.visitdenmark.es/es/copenhague/ atracciones/christian 